\title{
Comparing instrumental and deliberative paradigms underpinning the assessment of social values for cultural ecosystem services ${ }^{1}$
}

Christopher M. Raymond ${ }^{\mathrm{a}, \mathrm{b}, \mathrm{c}}$, Jasper O. Kenter ${ }^{\mathrm{d}}$, Tobias Plieninger ${ }^{\mathrm{e}}$, Nancy J. Turner ${ }^{\mathrm{f}}$, Karen A. Alexander ${ }^{\mathrm{d}}$

a Barbara Hardy Institute, University of South Australia, AustraliaUniversity of Copenhagen, Department of Geosciences and Natural Resource Management, Rolighedsvej 23, 1958 Frederiksberg C, Denmark

b Centre for Regulation and Market Analysis, School of Commerce, University of South Australia, Australia

c Enviroconnect, PO Box 190, Stirling, SA 5152, Australia

d Scottish Association for Marine Science, Scottish Marine Institute, Oban, Argyll PA37 1QA, UK

e Department of Geosciences and Natural Resource Management, University of Copenhagen, Rolighedsvej 23, 1958 Frederiksberg C, Denmark

f School of Environmental Studies, University of Victoria, PO Box 1700 STN CSC, Victoria, BC V8W 2Y2, Canada

\section{Keywords:}

Social values; Participatory mapping; Non-economic valuation; Non-monetary valuation; Ecosystem services; Deliberative valuation; Instrumental valuation

\section{Corresponding author:}

Christopher M. Raymond, Barbara Hardy Institute, University of South Australia, Australia / Centre for Regulation and Market Analysis, School of Commerce, University of South Australia, Australia / Enviroconnect, PO Box 190, Stirling, SA 5152, Australia (chris.raymond@enviroconnect.com.au)

\footnotetext{
${ }^{1}$ Preprint. Published Version: Christopher M. Raymond, Jasper O. Kenter, Tobias Plieninger, Nancy J. Turner, Karen A. Alexander (2014): Comparing instrumental and deliberative paradigms underpinning the assessment of social values for cultural ecosystem services. Ecological Economics 107: 145-156 http://dx.doi.org/10.1016/j.ecolecon.2014.07.033
} 


\begin{abstract}
Despite rapid advancements in the development of non-monetary techniques for the assessment of social values for ecosystem services, little research attention has been devoted to the evaluation of their underpinning paradigms. This study evaluates two contrasting paradigms for the assessment of social values in non-monetary terms: an instrumental paradigm involving an objective assessment of the distribution, type and/or intensity of values that individuals assign to the current state of ecosystems and a deliberative paradigm involving the exploration of desired end states through group discussion. We present and then justify through case examples two approaches for assessing social values for ecosystem services using the instrumental paradigm and two approaches using the deliberative paradigm. Each approach makes different assumptions about: the underlying rationale for values assessment; the process through which values are elicited; the type of representativeness sought, and; the degree of involvement of decision-makers. However, case examples demonstrate that the boundaries between instrumental and deliberative paradigms are often not concrete. To accommodate this fluidity, we offer a third, pragmatic paradigm that integrates some of the qualities of both. This paradigm has implications for engaging multiple community groups and decision-makers in the articulation and mapping of social values for cultural ecosystem services.
\end{abstract}




\section{Introduction}

Cultural ecosystem services produce a range of physical, emotional, and mental benefits that support human well-being (Kenter et al., 2011). These services are tightly linked to specific features of the material environment, as well as cultural practices and experiences (Bieling et al., 2014). Despite the importance of cultural ecosystem services being consistently recognized (e.g., Chan et al., 2012a, Chan et al., 2012b, MEA, 2005 and Plieninger and Bieling, 2012), existing monetary frameworks for representing or assessing them: 1) do not allow for a sufficient consideration of multiple dimensions and types of value (Chan et al., 2012b, Hernandez-Morcillo et al., 2013, Kenter et al., 2014 and Norgaard, 2010); 2) over-rely on standardisation and empirical valuation (Milcu et al., 2013); 3) ignore the wealth of cultural values research in the landscape planning literature (Schaich et al., 2010); 4) do not cater for multiple understandings of human-environment relationships which are tied to different cultural or industrial practices (Church et al., 2014, Flint et al., 2013, Kenter et al., under review and Raymond et al., 2013); and 5) do not usually consider subtle and implicit cultural benefits of the environment that nonetheless can have substantial value (Kenter et al., 2011). Frameworks that cater for the representation and assessment of intangible, and often incommensurable, value types may enable the engagement of a range of stakeholders (e.g., residents, planning decision-makers) in ecosystem management (Raymond et al., 2013) and assist in justifying the benefits of conserving and restoring a range of cultural services that may otherwise be subject to exploitation.

Non-economic assessments of ecosystem services have rapidly advanced in recent years (e.g., Fagerholm et al., 2012, Klain and Chan, 2012, Plieninger et al., 2013, Sherrouse et al., 2011 and Sherrouse et al., 2014). They typically engage local stakeholders in the identification and quantification of a broad range of 'social' and 'cultural' values for ecosystem services using participatory techniques such as Delphi surveys (e.g., Edwards et al., 2012), scenario analysis (e.g., Maes et al., 2012), Q method (e.g., Davies and Hodge, 2012 and Kerr and Swaffield, 2012), multi-criteria analysis (e.g., Karjalainen et al., 2013, Nahuelhual et al., 2013 and Verburg et al., 2014) and public participation GIS (e.g., Brown et al., 2011, Raymond et al., 2009, Sherrouse et al., 2011, Sherrouse et al., 2014 and Van Riper et al., 2012). While terms such as 'social' and 'cultural' value have been fuzzy, difficult to define and applied in different contexts (Ives and Kendal, 2014), the non-economic ecosystem services literature has tended to conceive social values expressed in non-monetary terms as a more pluralistic and heterogeneous alternative to economic conceptions of value (Kenter et al., 2014). Here, we define social values as the aggregate value to society, or, in operational terms, individual values for cultural ecosystem services aggregated to the societal scale.

Despite the recent growth of non-economic assessments of ecosystem services, the usefulness of these approaches has been little scrutinized. We are particularly concerned that assessments employ different methods of valuation without considering the perspective on rationality that underpins them. Most non-economic assessments of social values for ecosystems services follow an instrumental paradigm where the emphasis is on rating, ranking and spatially identifying social values (e.g., Brown et al., 2011, Raymond et al., 2009, Sherrouse et al., 2011 and Sherrouse et al., 2014); however, an equally important rationality is the 'deliberative' paradigm of knowledge and action (Forrester, 1999) which places emphasis on communication and argumentation, and combining lay and expert perspectives on the decision-making process (Stein and Harper, 2003). The contrasts between instrumental and deliberative assessments are likely to be particularly strong when assessing cultural ecosystem 
services, given the inherent subjectivity of cultural values and the high level of interest that local citizens have in them. These groups are likely to hold a variety of different knowledge systems and ways of identifying and assessing value (Raymond et al., 2010) that are likely to generate different outcomes from instrumental, survey-based techniques. The degree to which instrumental and deliberative approaches diverge may also depend on whether the valuation process is focused on assessing the values of a single interest, or aggregates the values of multiple representations - an issue of scale and diversity versus homogeneity.

In this study, we compare instrumental and deliberative paradigms, which explicitly or implicitly underpin most assessments of social values for ecosystem services. First, we develop a theoretical comparison, revolving around four axes: 1) perspective on rationality; 2) the process of value solicitation; 3) type of representativeness sought, and; 4) the degree of involvement of decision-makers. We then present and justify two approaches for assessing social values for ecosystem services following the instrumental paradigm and two approaches aligning with the deliberative paradigm, through case examples from marine, terrestrial and indigenous land management contexts. Our case example findings reveal that, in some instances, instrumental approaches integrate deliberative elements, and vice versa. However, such pragmatic approaches can lack theoretical coherence. It is rarely asked explicitly whether or not instrumental and deliberative paradigms can be synthesised in a meaningful way. The final part of this paper thus proposes a pragmatic paradigm for non-monetary valuation, which aims to integrate the strengths of both the deliberative and instrumental paradigms, and which is presented along the four axes described above.

The perspective we take in this paper draws on a post-normal science position introduced by Funtowicz and Ravetz (Funtowicz and Ravetz, 1991, Funtowicz and Ravetz, 1993, Funtowicz and Ravetz, 1994 and Ravetz, 1987). Post-normal science is based on "assumptions of unpredictability, incomplete control, and a plurality of legitimate perspectives" (Funtowicz and Ravetz, 1993, p. 739). Unpredictability - post-normal science recognises the uncertainties and value-laden nature of scientific practice and calls for participatory and ideologically open approaches to valuation and risk assessment ( Funtowicz and Ravetz, 1990 and Ravetz, 1987). Incomplete control - post-normal scientists support decentralised forms of political action and engagement approaches that are dialogic and empowering ( Bang, 2004). To this end, the environmental management literature provides frameworks to identify different types of stakeholders who may have an interest in or influence on ecosystem valuation ( Reed et al., 2009), as well as social processes to enhance the exchange and translation of local and scientific knowledge (e.g., Fischer et al., 2012), and principles for evaluating the effectiveness of the knowledge exchange process ( Fazey et al., 2014). Plurality of legitimate perspectives - post-normal science is committed to methodological pluralism ( Frame and Brown, 2008 and Raymond et al., 2010) and in this vein supports ecosystem service valuation methods that combine qualitative and quantitative forms of enquiry.

Pielke (2007) eloquently illustrates that scientists can adopt two broad roles to science: 1) a linear or 'normal' approach, which suggests that achieving agreement on scientific knowledge is necessary for political consensus to be reached and policy to be implemented, or 2) a stakeholder driven model, which emphasises stakeholders working together with researchers to engage with a range of experiences, knowledge and values to address a science problem. In this paper, we highlight possibilities for adopting instrumental approaches based on this linear approach to science, deliberative approaches based on a stakeholder driven model and pragmatic or post-normal approaches that combine the qualities of both. 


\section{Differences Between the Instrumental and Deliberative Paradigms}

Deliberative approaches can differ from instrumental ones along one or more of the four main axes mentioned in the Introduction, which are elaborated here (Table 1).

\subsection{Perspective on Rationality and Focus of Valuation}

The deliberative paradigm advocates communicative over instrumental rationality, where reasoned judgement to come to an agreement or decision is based on exchange of arguments bridging the moral and practical in a deliberative forum (Calhoun, 1992 and Habermas, 1984). Researchers who employ this deliberative paradigm consider that identifying approaches reflecting the common good is ultimately a question of communication, negotiation and 'aggregation by mutual consent' (Howarth and Wilson, 2006), rather than an exercise in maximising satisfaction of utilitarian preferences or trying to quantify results through summarizing questionnaire responses.

While instrumental approaches tend to focus solely on 'contextual' values and their indicators (e.g. monetary amounts, ratings, and rankings), deliberative approaches may consider both 'contextual' and 'transcendental' values. Kenter et al. (submitted for publication) define contextual values as opinions about worth or importance, which are dependent on an object of value. Transcendental values are the broader guiding principles or criteria used to select and justify actions across specific situations. These transcendental values are often implicit, shared and cultural. Deliberation allows for these values to become more explicit (Kenter et al., 2011) and for decisions to be made on the basis of a pluralistic ethical framework, potentially incorporating virtues, deontological notions such as rights and duties, and narrative-based ethics, as well as utilitarian/instrumental considerations (Kenter et al., 2014).

\subsection{The Process of Value Elicitation}

One of the strengths of the instrumental paradigm, regardless of whether it is applied through monetary or non-monetary methods, is that it can allow for the identification of gradients in preferences, expectations, needs, and desires towards ecosystem services; for example, on the basis of gender, lifestyles, or knowledge sources (Fagerholm and Käyhkö, 2009, Fagerholm et al., 2012 and Oteros-Rozas et al., 2014). By identifying gradients, instrumental methods can reveal trade-offs that arise from diverging interests and knowledge of different stakeholders and social groupings (Martín-López et al., 2012). When surveys are linked to Public Participation Geographic Information System (PPGIS) approaches, instruments are able to account for the spatial heterogeneity of values, attitudes and preferences; for example, through identification of hotspots, abundance, diversity, rarity, or risk of particular social values for ecosystem services across a landscape (Bryan et al., 2010 and Plieninger et al., 2013). However, the instrumental paradigm is often challenged by lack of clarity about how values, attitudes and preferences can be aggregated in an equitable way (Brown, 2012), and the choice of aggregation method is in itself a subjective and value-laden decision (Hockley, 2014, Kenter et al., under review and Kenter et al., 2014).

In contrast, the deliberative paradigm does not consider the knowledge collated or generated to be value-neutral or scientifically objective. It encourages the sharing of information among group members, resulting in a greater range of views being considered than what may have been thought about by any one individual (Spash, 2007). It also supports collaborative 
learning, acceptance of collaborative solutions and the building of shared understandings and mutual trust among participants (Frame and O'Connor, 2011). The paradigm reflects an assumption that values are not or not fully pre-formed, requiring at the least exchange of information and perspectives, and potentially a more extensive process of value construction (Kenter et al., 2014), whereas instrumental approaches often assume no particular need for social exchange to achieve rational outcomes. However, the process-dependent, subjective nature of social exchange can impede the integration of social values with conventional economic and biological assessments, where the focus is on the use of standardised instruments and measures of value that are independently assessed and verified.

Given the focus on sharing of information, deliberative approaches are more effective than instrumental approaches in allowing an understanding of the social interactions that occur between social groups with different interests. In the wider literature, social representation theory describes the process through which shared realities are established and sustained in social groups. Moscovici (1972) explains that social representations are "a system of values, ideas and practices", that serve (a) to establish a social order that enables individuals to orientate themselves and master the material and social world they live in, and (b) to enable communication among members of a community through a shared code for social exchange and for naming and classifying various aspects of the social world including their individual and group history (p. xiii). Hence, social representations enable the achievement of a shared social reality (Moscovici, 1988), and are created to place objects, persons and events into a familiar context. They also influence social behaviour and social interaction, as supported by studies on psychoanalysis and public understanding of science (Gaskell, 2001). Each representation (e.g., a conservation group) familiarizes the unfamiliar by the related processes of anchoring and objectifying (Moscovici, 1984). Anchoring involves the naming and classifying of encounters, ideals, things or persons. Objectification makes the abstract tangible.

\subsection{Type of Representativeness Sought}

While instrumental techniques allow statistically representative samples of individuals to assign values, deliberative techniques often involve selecting people to act as representatives of their stakeholder group or of society as a whole, who are empowered to appraise or advise on decisions on behalf of the collective. Optimal representation in instrumental approaches is based on ensuring that survey responses are reflective of the wider population of interest, or interview responses provide for sufficient saturation of the suite of themes and sub-themes related to a particular phenomenon. Conversely, in deliberative approaches it has to do with the effective involvement of all key stakeholders. Given the focus on statistical representation, instrumental approaches allow for sub-group analyses whereby the values of one social group are compared and contrasted to another. Deliberative approaches often (but not always) employ smaller sample sizes than instrumental approaches. As a result, sub-group analysis is likely to be more challenging, or may not be appropriate. Further, small groups are subject to the perils of "group-think" and can be dominated by a few powerful individuals (Dietz et al., 2009, Janis, 1972 and Maier, 1967) potentially introducing a social desirability bias into information about ecosystem services (Kaplowitz and Hoehn, 2001). As a result of these representation differences, instrumental and deliberative techniques could generate very different outcomes on what constitutes the collective good. 


\subsection{Degree of Involvement of Decision-makers}

In the deliberative paradigm, decision-makers are often actively engaged in valuation at multiple phases of the project. They inform the social and environmental contexts to the problem, and may be actively engaged in the identification, rating or rankings of values. Consequently, the separation between processes of evidence gathering and decision-making is less clearly delineated than in instrumental approaches. In the latter approach, decisionmakers are generally engaged after the completion of the assessment and advised on how the value outputs can be used to inform policy and planning.

The instrumental paradigm espouses that objectivity can be attained, and focuses on the importance of internal and external validation of study findings. As noted above, researchers pay close attention to the random sampling of local people to be involved in the study with the goal that the outputs of the study (e.g., spatial representation of aesthetic or recreation values) will be representative of wider community views (assuming an adequate survey response). Decision-makers are generally kept out of this process, as researchers strive to minimise bias in the results. Conversely, the deliberative paradigm attends to achieve legitimacy through transdisciplinarity; through involvement of decision-makers in defining questions and evaluating solutions it is deemed more likely that evidence from these processes will be taken up in arriving at decisions.

\section{Contrasting Approaches for Assessing Social Values for Ecosystem Services}

Based on the four axes elaborated in the previous section, we now present contrasting examples of instrumental and deliberative approaches for assessing social values for ecosystem services. We first highlight two approaches to the instrumental assessment of social values for ecosystem services. The first approach assumes that there is no heterogeneity in the survey population and the second approach assumes representation from different social groups. We then present two approaches to the deliberative assessment of social values for ecosystem services (i.e., approaches three and four). Approach three assumes that individuals from a similar social representation (e.g., multiple agencies representing conservation interests) are invited to share their values or preferences in a group-based environment, whereas approach four assumes values sharing across individuals from different social representations (e.g., conservation and development). Both approaches three and four recognise the importance of interactions between individuals and groups of shared or divergent interests.

\subsection{Approach 1: Instrumental Valuation Which Assumes a Homogenous Survey Population}

In this approach, the subjects (study participants) are asked to independently self-report or map their social values for ecosystem services, among other landscape attributes, using a range of techniques including mail-based surveys, electronic surveys, individual-based workshop assignments or individual interviews (Raymond et al., 2009 and Raymond and Brown, 2011). Survey or interview responses or spatial markers of value (points, lines or polygons) are statistically aggregated to a regional, national or global scale with limited or no sub-group comparison (Fig. 1). Often, the researcher conducts a variety of analyses, which may include the identification of areas of abundant, rare or diverse social value, with little engagement with the decision-maker (Bryan et al., 2010). A variety of spatial models can be 
generated to assist with the spatial prediction of land-use allocations (Raymond and Brown, 2006), the identification of potential for land-use conflicts (Brown and Raymond, 2014 and Nielsen-Pincus et al., 2010), the prediction of areas suitable for different land management activities (Sherrouse et al., 2011 and Van Riper et al., 2012), description of patterns in the spatial distribution of ecosystem service bundles (Plieninger et al., 2013 and Raymond et al., 2009), and comparing scientifically assessed values for ecosystem services to priorities based on social value (Alessa et al., 2008, Bryan et al., 2011 and Whitehead et al., 2014).

Case example 1: Assessment of social values for cultural ecosystem services at the local scale in a lowland area of Eastern Germany

Local residents of five villages in Eastern Germany were examined in the case example by Plieninger et al. (2013), which is a typical example of an instrumental non-monetary valuation of ecosystem services. The villages are situated within the Upper Lusatia Pond and Heath Landscape Biosphere Reserve. Taken together, the five villages comprise 1188 inhabitants and cover 1950 ha. The area has one of the lowest population densities in Germany, and population numbers decreased substantially in the post-socialist period (after 1990). Ninetythree individual subjects of a relatively homogenous group (local residents) independently assessed 14 different pre-determined cultural services that they attributed to specific land features (objects) in their local landscapes. Cultural services were assessed through face-toface interviews which centred on variants of the following question: "Where in this area do you find or use cultural service benefit X?" For example, to gather aesthetic values, study participants were asked: "Where in your community do you enjoy the beauty of the landscape?"

Participants were asked both about experiential connections (e.g., spiritual services) and activity-based values (e.g., recreation), and about the relationships between them (e.g., hiking and scenic values). For a collective representation of the cultural services that the local landscape offered to residents, data were aggregated in maps and through quantitative analysis. Frequency maps were generated that allowed identification of "hot spots" of particular cultural ecosystem services in the landscape. Moreover, aggregated maps of intensity, richness and diversity of the full set of cultural ecosystem services were created using indices borrowed from the ecology literature. Some trends in valuation depending on gender, age groups, professional background, etc. were explored, but no explicit sub-group analysis was performed and the heterogeneity among a broader set of people (e.g. residents, tourists, farmers, environmentalists) was not considered.

The mapping exercise was a pilot study to develop and test a methodology, and immediate uptake in protected area planning and management was not an explicit objective. Therefore, results have met with interest from the agency managing the protected area, but they have not been used for concrete planning or management purposes in the protected area.

\subsection{Approach 2: Instrumental Valuation Which Assumes Heterogeneity in the Survey Population}

The instrumental paradigm also provides for sub-group comparisons (Fig. 2), such as comparing the distribution and type of social values assigned by conservation and development interests. These social representations are likely to have differences in their 
values for, knowledge of and interests in ecosystem services and their management. When statistically compared or spatially overlayed, there is the potential for not only overlapping, but also potentially conflicting contextual values.

It is possible that each sub-group has different levels of political influence on the ecosystem management problem. The instrumental paradigm does not usually account for these political interests in the statistical aggregation process. In most studies on social values assessment to date, values of different sub-groups have been equally weighted and assessed on an equal basis. Similarly, this instrumental approach does not account for institutional contexts, including the different abilities of social representations to express their social values, and the power dynamics between different social groups that enable some types of values to be privileged over others.

Expert panel reviews, such as the one which will be described in case example 2, below, often take on this valuation approach. Researchers are engaged to conduct social or economic impact assessments. Social values, among other attributes, are identified, described and/or quantified using individual instruments such as survey and interviews, and then aggregated. The results are compiled into reports that present the responses of different sub-groups. The reports are then presented to the expert panel, with little opportunity for discussion or the sharing of values, knowledge and interests among groups. While it could be argued that experts deliberate among themselves, there is an assumption of instrumental rationality. That is, experts acting as supposedly value-neutral arbiters commensurate different interests and come to an 'objective' conclusion on the basis of their assumed superior knowledge and insight. Values between different representations can be shared, divergent or conflicting. For evaluation, values are implicitly or explicitly reported to the expert panel and/or to decisionmakers, who are not actively engaged in the analyses.

Case example 2: Assessment of cultural impacts of the Enbridge Northern Gateway proposal on multiple social representations in northern British Columbia

In 2006, Enbridge, an oil pipeline company based in Alberta, Canada, announced interest in building a twin pipeline system - "Northern Gateway" - from the oil sands extraction region of northern Alberta near Edmonton across the province of British Columbia (BC) to a new marine terminal in Kitimat on the northern BC coast. In considering whether the Northern Gateway project (ENGP) should be allowed to proceed, the Canadian Environmental Assessment Agency (CEAA) and the National Energy Board (NEB) established a threemember Joint Review Panel (JRP) to hear evidence and perspectives from multiple social representations, including multiple First Nations communities (e.g., the Gitga'at First Nation) with territories along or near the proposed route of the pipelines and tanker routes, politicians, conservation scientists, a range of environmental NGOs, as well as groups representing forestry, fishing, recreation, business, agriculture, medicine, engineering and education.

As part of the response process, professional reports were also prepared on behalf of First Nations and environmental organisations, with research focusing on the potential environmental, social, economic and cultural impacts of the pipelines and tanker traffic. Of these, one of the authors (NT) was a co-author on the Cultural Impacts report for the Gitga'at First Nation, whose territory straddles the proposed tanker route through Douglas Channel and outer inlets (see Satterfield et al., 2011). 
The Cultural Impacts Study involved an instrumental assessment of how the Gitga'at people perceived the potential impacts of the ENGP on their culture (Satterfield et al., 2011). To understand the social values ascribed to cultural ecosystem services, an open-ended interview protocol was established to reveal important categories of Gitga'at culture (i.e., cultural significance of food and family, harvesting and use; knowledge transmission; feasting; and cultural landscapes), from which specific interview questions were then developed for further interviews with members of the Gitga'at Nation. This preliminary work also informed one section of the "Social Impact Survey" (Gill and Ritchie, 2011). These were questions pertaining to how Gitga'at were defining cultural identity for themselves - literally, what it meant to them to "be Gitga'at."

The interview responses were statistically aggregated and indices were applied to assess cultural significance of particular species or sites (based on interviews and previous research) and anticipated impacts from potential small, medium or large oil or condensate spills. Local observations regarding shipping, wakes and pollution were also noted. For spill scenarios, modelling projections provided by Bocking et al. (2011) were superimposed on harvest maps analysed and spatially expressed. The interviews revealed strongly shared values of all respondents regarding the high importance of all of the cultural categories (harvesting local food, intergenerational teachings, feasting, and the integrity of cultural landscapes and seascapes in Gitga'at territory). Findings also revealed that cultural identity - "Being Gitka'a'ata" and following a "Gitka'a'ata Way of Life" - was almost universally identified as critically important to community members. For the Gitga'at and other First Nations, Northern Gateway represented, right from the outset, a huge risk to their cultural survival, with threats of oil spills and resulting contamination that would damage their food sources and key habitats of high cultural importance. In short, there was general strong opposition among First Nations to the Enbridge Project and fears expressed about its potential impacts.

Separate to this socio-economic assessment of the tankers, Enbridge Northern Gateway Pipelines (2010) conducted a socio-economic impact assessment of the construction and decommissioning of the pipeline. The assessment focused on designated protection and recreation areas, consumptive and non-consumptive recreation, and aesthetic resource values. Here we focus on the trapping, hunting and recreation industries. Outdoor recreation clubs and private landholders were invited to share their values and perceived impacts of the project using instrumental assessment techniques such as telephone discussions, interviews and questionnaires. Measured parameters included the disruption of trapping, hunting and fishing activities. The views shared by the hunting and fishing representations were aggregated into themes and sub-themes. Individuals raised concerns that the pipeline's construction may disturb furbearing and game animals, damage or encroach on trail systems and trapping sites, fragment habitat and inhibit certain species from crossing trapping sites.

Given the different geographic boundaries of the tanker and the pipeline studies, it was challenging in this case to statistically aggregate the social values identified by the different social representations. Nonetheless, study findings reveal that both First Nation and nonindigenous groups assigned a suite of social values to cultural ecosystem services, which were perceived to be impacted by the proposed development. According to the Pacific Wild website, of the total written submissions to the Joint Review Panel, 9159 were against Northern Gateway, 239 supported the project, and 169 were unclear or undecided (Pacific Wild, 2014). Nevertheless, in December 2013 the Joint Review Panel for the proposed Enbridge Northern Gateway Project recommended that the federal government approve the 
project, although subject to 209 required conditions (National Energy Board, 2013). In turn, in mid-June, 2014, the federal government agreed to let Enbridge build its Northern Gateway pipeline, subject to the 209 conditions recommended by the National Energy Board and to further talks with Aboriginal communities (CBC, 2014).

\subsection{Approach 3: Deliberative Valuation of Social Values Within a Social Representation}

In this approach, individuals from a similar representation (e.g., multiple agencies representing conservation interests) are invited to share their values or preferences in a groupbased environment, such as through a workshop or focus group (Fig. 3). The deliberative process could include scientists, end users and decision makers, either to inform valuation, or even as participants (as in case example 3, below). Discussions often do not just focus on contextual values, but may also consider questions around transcendental values, issues of fairness, responsibility, uncertainty and risk. Emphasis on risk and uncertainty is a feature of post-normal science, as outlined previously, but is also supported by cultural risk theory. This suggests that risks are most effectively managed by engaging communities in a dialogue about their shared confidence and shared fears, and how best to organise social relations in response to new risks (Douglas and Wildavsky, 1983). Comparatively few participatory techniques for the non-economic assessment of social values for ecosystem services have accounted for the influence of social interactions among individuals of similar social representation. Here, it is likely that participants will have a degree of similarity in their transcendental values, and overlapping frames of perception around the issues at stake and risks to be managed. This means that the main focus of the deliberative process is likely to be on enhancing understanding of the context, and making linkages between transcendental values and the context to form contextual values (Kenter et al., 2014). In this case, there is considerable potential for establishment of deliberated group values through consensus or compromise on what constitute shared social values, although the possibility of plural, incommensurable and potentially conflicting values remains.

Case example 3: Deliberative valuation of ecosystem services by community councils around the Forth Estuary, Central Scotland

This case example, which was part of the second phase of the UK National Ecosystem Assessment (Church et al., 2014, Kenter et al., 2014 and UK NEA, 2014), used an approach combining deliberative monetary valuation (DMV) and participatory mapping to understand the value of the Inner Forth Estuary ecosystem services and landscape. Objectives of the project included: analysing the economic benefits of ecosystem services that might be delivered by two conservation projects, understanding what places and features are most valued by local communities and how management could be improved, generating social learning and developing a better understanding of deliberative processes. The study evaluated proposals associated with the Inner Forth Futurescape and Inner Forth Landscape Initiative (IFLI) projects. The Futurescape revolved around a number of coastal realignment and conservation habitat creation/restoration proposals. The IFLI focused on community-led regeneration of the landscape, mixing cultural and environmental initiatives. The single representation highlighted by this study consisted of local communities represented by 52 community councillors, participating in nine workshops across the region. Community councils are the lowest tier of Government in Scotland. They do not wield significant formal 
power, and their main role is as statutory consultees in planning affairs. Although the group of councillors was diverse demographically and in terms of political beliefs, they fundamentally represented the same overall interest of protecting and enhancing local community rights and entitlements.

Workshops were facilitated jointly by one of the authors (JK), a researcher, and by the IFLI project manager. The DMV component of the workshop consisted of deliberation on individual and group-based choice experiment questions. To stimulate deliberation, participants were asked explicitly about their most important transcendental values. They also completed a conceptual systems modelling exercise, which helped participants make connections between the projects, ecosystem services, and their role within the socialecological system. In the non-monetary valuation, small groups were asked to discuss and point out, as a group, which features (natural or man-made) within the IFLI project boundary were interesting, special, or should be conserved, and which features were problematic. The groups were then asked to rank them in order of importance. The aim of this exercise was to gather practical, spatially explicit information on cultural services that would be of direct use to the IFLI.

The combination of mapping and ranking proved to be a useful and practical tool in terms of conveying priorities for management measures. Participants themselves expressed that they experienced the mapping as satisfying, adding a more concrete element to the relatively abstract monetary valuation session. In discussions during the DMV, participants placed conservation and landscape improvement in a context of fairness by considering that local people did not have the resources to go and recreate elsewhere. The process of deliberative mapping served to articulate different values, influencing how participants viewed and felt about the Inner Forth. "I was surprised we came to much more green than red dots. This is not an area that people know for being attractive. It is not really beautiful in the way that people usually think about places like the Highlands or the west coast. But looking at it this way I feel quite proud of this place."

\subsection{Approach 4: Deliberative Valuation of Social Values Across Social Representations}

A fourth approach is where individuals representing multiple social representations express their values in a group environment (Fig. 4). In this context, the vested interests of different social representations are likely to heavily influence the valuation process. Bauer and Gaskell (2008) expanded social representation theory to show that representation is also a function of the intergroup context. Representations are formed in relation to other communities that are potentially competing groups, possibly of unequal power. The valuation of ecosystem services therefore depends on the intersection of these different social representations. More complex deliberative valuation techniques attempt to understand how these different social groups interlock and create a future of no one's particular design. Researchers and decision makers can inform the process through the provision of background information, or even as representatives of their social interest groups, but how this information will shape the values and preferences of participants involved in the deliberative valuation will depend strongly on the relative influence of different stakes and how power issues are managed. Stakeholder participation does not occur in a power vacuum and there is potential for participation to reinforce existing privileges and group dynamics and marginalise quiet voices (Cooke, 2001 and Kothari, 2001). Interactions between different social groups may first lead to argumentation, but through effective facilitation, communication with participants, goal 
setting and planning, can lead to negotiation and compromise or consensus (Reed, 2008); potentially with higher quality outcomes that are more broadly supported than without such processes (Beierle, 2002 and Sultana and Abeyasekera, 2008).

To elicit social values for cultural ecosystem services in this context, researchers need to understand how different social representations both relate to one another and reflect the place-based features of the ecosystem and landscape. In many cases, it may be possible to achieve a level of consensus on the nature and distribution of values within a social representation (through the engagement of a skilled facilitator, as shown in Fig. 3), but it is substantially more challenging to achieve consensus across diverse representations, with possibly only a limited area of shared concern and interest (Fig. 4). This creates complications for the development of a standardised set of social values for evaluating cultural ecosystem services. Environmental managers need to consider not only spaces of shared, plural and conflicting values, but also power dynamics in relation to how those values are expressed and considered within environmental policy making and decision making. This kind of process is likely to take substantially more time and to be more complicated than a deliberative process with a single representation. It is particularly important to gradually develop the process in relatively value-neutral territory, involving joint analysis and trust building, before commencing evaluative exercises (Kenter et al., 2014 and Raymond et al., 2013).

\section{Case example 4: Deliberative valuation to guide the optimal location for a tidal energy development at the Mull of Kintyre, West Scotland}

The seas around Scotland have considerable potential to generate marine renewable energy. To facilitate the capture of this energy, a number of seabed leases have been proposed around the Scottish coast, with an area to the west of the Mull of Kintyre being one of the areas recommended as a potential tidal energy site. A study by Alexander et al. (2012) tested a method to identify suitable locations for tidal energy devices within the proposed lease site, using a combination of GIS, multi-criteria analysis and a touch-table to facilitate stakeholder dialogue in a workshop setting. A touch-table is a large, table mounted, touchscreen computer. Participants can directly interact with what is displayed, such as maps. The key objectives of this study were to gather spatial information regarding use values across a number of social representations, to identify potential conflicts and to develop a mechanism to support negotiation for planning of tidal energy extraction through a deliberative process.

Social representations were identified as likely to be affected by tidal energy extraction at this site including not only commercial fishing, shipping and tourism, but also recreation and cultural and natural heritage groups. Little spatial data to facilitate planning was available initially. Therefore two workshops were organised that included representatives from each of the above social representations where possible. The first 'Local Knowledge' workshop focused upon improving data-poor stakeholder value maps, by asking participants to draw and rank areas on maps, and identify potential areas of conflict. The second 'Negotiation' workshop aimed to locate optimal areas for the location of tidal energy extraction (under three scenarios) with the least possible damage to the interests of other users. As participants had little understanding of the concept of tidal energy, researchers provided advance background information regarding tidal energy, tidal energy devices and uses of the marine environment in the location. The study did not aim to inform decision-making around an actual project, and therefore the involvement of decision-makers was limited to observing the 'Negotiation' workshop. 
A key finding of the first, local knowledge workshop was that participants found it difficult to rank the areas used in terms of importance. Discussions suggested that the areas were used in different ways, e.g. at different times of year and in different types of weather. During the second, negotiation workshop, shared values became more evident. Many participants felt that the 'long-term' view was important when planning in the marine environment and that issues relating to 'private control' of the sea needed addressing based on the shared belief that marine environment is a common resource. Deliberation also brought forward important transcendental values relating to precedence and responsibility. The combination of tools with the stakeholder workshop format allowed participants to view the 'bigger picture' and not to focus purely on their own areas of interest. During both workshops all contributors were involved in working with all value maps, participants shared ideas, reflected, asked each other questions and brought up pertinent points which were then developed by others. As a result of deliberation and social learning, which provided all representations an opportunity to gain a holistic view of the issue, stakeholders with opposing perspectives successfully managed to identify areas where tidal devices could be situated with minimal disruption to existing activities. This consensus view surprised the research team and is unlikely to occur when deliberating on more politically contentious proposals, such as proposals for coal-seam gas development.

\section{A Pragmatic Paradigm for the Assessment of Social Values for Cultural Ecosystem Services}

While the four case examples presented above clearly illustrate different rationalities, valuation processes, types of representation and degrees of involvement of decision-makers, they also indicate that in reality the boundaries between the four presented approaches are more fluid than might be apparent from the paradigmatic archetypes presented. For example, in the Canadian case (case 2), deliberative assessments such as focus groups and workshops were also undertaken by researchers involved in the cultural impact assessment study and the wider socio-economic impact assessment, even though it was not clear how the outputs of these deliberative assessments informed the final recommendations of the joint review expert panel. Similarly, in case 4, instrumental approaches were used to 'kick-start' the deliberative process. These fluid boundaries indicate a need for a pragmatic valuation paradigm that can theoretically ground how to integrate qualities of both instrumental and deliberative valuation approaches (Table 2). In simple terms, it appears that pragmatic approaches undertake instrumental assessments that are integrated and/or appraised through deliberation (Instrumental $\rightarrow$ Deliberative), or where group aggregation and appraisal precede an instrumental approach (Deliberative $\rightarrow$ Instrumental). However, without a clear theoretical foundation of how deliberative and instrumental approaches might be integrated, it is unclear what criteria can be used to evaluate validity and legitimacy of these approaches. A pragmatic approach thus risks incoherence and haphazardness.

In the following sections, we propose a pragmatic paradigm to address these concerns. We will show that the order of consideration of each rationality (i.e., Instrumental $\rightarrow$ Deliberative or Deliberative $\rightarrow$ Instrumental) will in-turn influence the process of value elicitation, type of representation, and the degree of involvement of the decision-maker.

\subsection{Perspective on Rationality}


It is clear that instrumental and deliberative paradigms have some fundamentally different assumptions about questions of rationality and the epistemological considerations that underpin this. Instrumental rationality is benefit-driven, and what is considered rational relates to trading-off and maximising preferences, which, it is assumed, can be measured objectively. Conversely, communicative rationality, which underpins deliberative paradigms, considers that what is rational is highly dependent on positions and contexts, and that a process of rational communication and deliberation is the most appropriate form of appraisal. The pragmatic paradigm incorporates a pluralistic conception of rationality that indicates that arithmetic, utilitarian approaches can provide evidence that can usefully inform decisionmaking, but are not comprehensive and remain open to debate. Crucially, a pragmatic paradigm acknowledges that the choice of aggregation method to identify social values implies value judgements, and that results can thus be challenged on this ground. This means that instrumental valuations can provide useful data on relative values associated with different social representations, but that consideration of trade-offs between different stakes and different dimensions of value needs to be subject to debate and negotiation, carefully accounting for differences in power and other institutional considerations. There are two broad possible ways to provide options for debate: to enable individual assessments of value to inform communication of value and shared realities (Instrumental $\rightarrow$ Deliberative) or to provide for the sharing of realities first followed by cross-validation using instrumental assessments (Deliberative $\rightarrow$ Instrumental, Table 2). In terms of epistemology, this pragmatic paradigm allows for plurality in views on the degrees of objectivity of knowledge. As such, the pragmatic paradigm could be related to the philosophy of transcendental realism whereby knowledge of reality is informed both by concrete structures (e.g., physical evidence), and by social constructions (Raymond et al., 2010).

\subsection{Process of Value Elicitation}

A pragmatic paradigm provides an opportunity to combine value elicitation methods. However discussion of modes of rationality above indicates that the order in which this is done is crucial. In Instrumental $\rightarrow$ Deliberative assessments, values would be elicited from individuals and then debated and negotiated in a group process. In Deliberative $\rightarrow$ Instrumental assessments, values would be both elicited and negotiated in groups, but then validated through an instrumental assessment.

In Instrumental $\rightarrow$ Deliberative assessments, the initial aggregation would typically be partial: individual values may be aggregated within a representation or value type, but the weighing of values across representations or potentially incommensurable value types (e.g. use and non-use values) would be up for discussion. Thus, in the deliberative part of the assessment, the means of aggregation can be made transparent, critiqued and negotiated (e.g. in terms of the weight given to different stakes and dimensions of value). In the Deliberative $\rightarrow$ Instrumental approach, values are both elicited and negotiated through deliberation (e.g., as in case example 4). Values and outcomes, such as a ranking of policy options, may then be put to a representative sample of stakeholders or interested individuals or groups for validation.

\subsection{Type of Representation}

The nature of the sampling technique and the tests of representativeness employed will also influence the types of social values collated. Social values collated through an Instrumental $\rightarrow$ 
Deliberative assessment are often underpinned by probabilistic sampling techniques whereby everyone in the region has an equal chance of being selected. Values aggregated from a statistically representative sample of individual values inform a politically representative, deliberative process. In contrast, social values collated through a Deliberative $\rightarrow$ Instrumental assessment are initially elicited through workshops where a small number of participants are asked to speak on behalf of a social representation. As noted above, their values and outcomes can then be cross-checked through individualistic methods (typically surveys) to consider the degree of agreement by a demographically and socio-economically representative sample.

Stratified forms of sampling are also important with respect to the social valuation of ecosystem services, particularly when some groups are likely to be affected by an ecosystem management decision more than the wider regional population. For example, in Australia and Canada indigenous people have legal rights to consultation under respective land rights legislation to ensure that they are properly represented during development proposals. In such cases, it is important to stratify groups, adequately sample within them, and systematically integrate their values within planning and decision making. The social valuation approach in case example 2 was largely unsatisfactory to First Nations people because they felt that their values were not heard, nor adequately considered in the pipeline and coastal development decision making process. We believe that a pragmatic paradigm, following either an Instrumental $\rightarrow$ Deliberative or Deliberative $\rightarrow$ Instrumental assessment would have provided greater scope for First Nations, among other social representations highly affected by the oil and gas developments, to openly share their values with expert panel decision-makers. Rather than merely reporting on their values and the perceived impacts of development, a deliberative process of values sharing and social learning could have occurred across representations, with decision-makers present as observers and contributors to the discussion. This sharing and learning may have then led to processes of negotiation which provided more equitable benefits across all representations, potentially obviating the need for lengthy court proceedings which essentially decide on 'winners' and 'losers'.

Another benefit of the pragmatic paradigm is that the locus of power and level of influence in the valuation is balanced between representative samples, political representations, and the researchers that manage the process, though the emphasis varies according to the approach that is adopted. Instrumental $\rightarrow$ Deliberative assessments emphasise representative assessments of value, aggregated to the societal scale. Group-based sharing of values is guided by the instrumental assessments, shifting the emphasis of power to the individuals who participated in the interviews or surveys prior to the deliberative process and the researcher(s) responsible for aggregating and reporting on the responses. In contrast, a Deliberative $\rightarrow$ Instrumental assessment tilts the balance of power in favour of the social representations invited to a deliberative workshop and their individual representatives. As in the deliberative paradigm, the degree to which processes on the basis of the pragmatic paradigm are effective strongly depends on the quality of process design, stakeholder management and facilitation.

Thus, the pragmatic paradigm is able to represent and integrate contrasting democratic ideals: that of 'one person, one vote', and the Habermasian democratic ideal of the resolution of conflict through democratic debate, where democracy is expressed through engagement and empowerment of all those affected by decisions and rational debate between them.

From this perspective, it would be interesting to compare and contrast Instrumental $\rightarrow$ Deliberative vs Deliberative $\rightarrow$ Instrumental assessments, which, to our understanding, have not been undertaken in the non-economic (or economic) environmental valuation literature. 


\subsection{Degree of Involvement of Decision-makers}

The pragmatic paradigm involves a degree of transdisciplinarity, involving decision-makers both in the framing of the valuation and, where appropriate, as participants in deliberative processes. How decision-makers 'partner' in the deliberation is a key question which needs to be considered as part of an assessment. However, in the instrumental individual surveying phase, which is used to either inform deliberation or validate its outcomes, the role of decision-makers is limited in order to reduce the potential for bias or politicisation of survey results. In the Deliberative $\rightarrow$ Instrumental paradigm, the degree of objectivity or neutrality of the surveys undertaken can itself be a point of debate within the deliberative phase. The key benefits of a pragmatic paradigm are that involvement of decision-makers on the one hand is likely to enhance impact of the research on decisions, while on the other hand elements of the approach are to a degree insulated from politicisation, reducing bias.

\section{Conclusions}

This paper outlined, and justified through case examples, how the non-economic assessments of social values for cultural ecosystem services are underpinned by different paradigms, articulated as instrumental and deliberative. We distinguished between instrumental and deliberative paradigms based on four axes of: 1) perspective on rationality; 2) the process through which values are solicited; 3) type of representativeness sought, and; 4) the degree of involvement of decision-makers. Both deliberative and instrumental paradigms can involve single or multiple social representations, which also has a bearing on how values are elicited and aggregated. Our case examples thus exemplified two types of instrumental and two types of deliberative approaches for assessing social values, illustrating different types of social groups surveyed, and methods of value elicitation and aggregation and engagement of social representation in ecosystem management problems. Reflexive analysis reveals that, despite distinctly different rationalities, the boundaries between instrumental and deliberative paradigms are, in practice, fluid. However, pragmatic approaches as applied often lack a cohesive theoretical framing. To address this, we highlighted the salience of a third, pragmatic paradigm that integrates both deliberative and instrumental qualities. The pragmatic paradigm can underpin both Instrumental $\rightarrow$ Deliberative and Deliberative $\rightarrow$ Instrumental assessments.

Each of the paradigms has its strengths and weaknesses, and, from a pragmatic perspective, which paradigm is more appropriate is context-dependent. Ultimately, the choice of paradigm and methods needs to be accepted by the participants, by end-users of the evidence (e.g., decision-makers) and by society as a whole. In monetary valuation, resistance against the instrumental paradigm is regularly pronounced, both by participants refusing to state their willingness to pay, and by commentators within and outside academia. The debate now appears to start drawing pragmatic conclusions around when monetary valuation is appropriate and when it is not (Kallis et al., 2013). In relation to non-monetary valuation, we also suggest that researchers embrace a variety of perspectives to ensure that their results both reflect a diversity of understandings of human-environment relationships and engage a diversity of interests and perspectives in ecosystem-based management (Raymond et al., 2013). Generally, it can be said that the advantages of the deliberative paradigm are most pertinent in cases where situations are complex and/or contested (Kenter et al., 2014 and UK NEA, 2014). 
However, in many cases a pragmatic paradigm has several distinct advantages. By making the goals of the ecosystem-based management explicit, researchers may be able to better choose how they combine and tailor approaches to address the management problem. The approach can integrate both representative and deliberative democratic ideals. It can engage with decision-makers, enhancing impact, but balances this with the need to generate outcomes with a degree of neutrality. It may also assist in engaging a greater diversity of stakeholders in ecosystem-based management and provide forums for systematically understanding how political interest and power differentials across social representations influence ecosystembased management decisions. Instrumental $\rightarrow$ Deliberative assessments can harness the strength of instrumental approaches to gather large amounts of data cost-effectively through surveys, while taking advantage of deliberation for negotiating trade-offs and dealing with incommensurable values, rather than through arbitrary statistical means. Deliberative $\rightarrow$ Instrumental assessments also utilise these strengths of deliberation, but add a stage of representative democratic validation to enhance legitimacy.

The benefits of this paradigm have yet to be empirically examined within an ecosystem services context. How combinations of different approaches may influence the distribution, type and intensity of social values on the landscape requires examination. We recommend that future studies compare and contrast the comprehensiveness, efficacy and perceived legitimacy of the social values elicited from the same subjects during instrumental, deliberative and pragmatic non-monetary valuation. This could be achieved by arranging three treatments of: 1) social values derived from aggregated individual surveys or interviews; 2) social values elicited through group-based deliberation; and 3) social values elicited through surveys or interviews, in turn informing a group-based deliberative setting. Controls would need to be implemented to manage subject differences. We encourage such comparative studies, in addition to multiple-phased mixed-method designs that compare the influence of using Instrumental $\rightarrow$ Deliberative vs Deliberative $\rightarrow$ Instrumental assessments on the nature of social values for cultural ecosystem services.

\section{Acknowledgements}

We would like to thank Prof Terre Satterfield (University of British Columbia) for contributing important insights to the Enbridge Northern Gateway case example. Tobias Plieninger was funded by the European Community's Seventh Framework Programme under Grant Agreement No. 603447 (Project HERCULES). The Inner Forth case example was part of the UK National Ecosystem Assessment (Work Packages 4: Cultural Services, and 5: Shared, Plural and Cultural Values) funded by the UK Department of the Environment, Food and Rural Affairs, the Welsh Government, and the Natural Environment, Economic and Social, and Arts and Humanities Research Councils.

\section{References}

Alessa, L., Kliskey, A., Brown, G., 2008. Social-ecological hotspots mapping: A spatial approach for identifying coupled social-ecological space. Landsc. Urban Plan. 85, 2739.

Alexander, K.A., Janssen, R., Arciniegas, G., O'Higgins, T.G., Eikelboom, T., Wilding, T.A., 2012. Interactive marine spatial planning: Siting tidal energy arrays around the Mull of Kintyre. PLoS ONE 7 (1), e30031. 
Bang, H.P., 2004. Culture governance: Governing self-reflexivemodernity. Public Adm. 82, 157-190. Bauer, M.W., Gaskell, G., 2008. Social representations Theory: A progressive research programme for Social Psychology. J. Theory Soc. Behav. 38, $335-353$.

Beierle, T.C., 2002. The quality of stakeholder-based decisions. Risk Anal. 22, 739-749.

Bieling, C., Plieninger, T., Pirker, H., Vogl, C.R., 2014. Linkages between landscapes and human well-being: An empirical exploration with short interviews. Ecol. Econ. 105, $19-30$.

Bocking, R., Demarchi, M., Plate, E., Holst,M., Muir, J., 2011. Reviewof the Enbridge Northern Gateway Project. Unpublished Report. Submission to the Joint Review Panel for Review of the Enbridge Northern Gateway Project, on behalf of the Gitga' at First Nation, (Hartley Bay, BC).

Brown, G., 2012. Public Participation GIS (PPGIS) for regional and environmental planning: Reflections on a decade of empirical research. URISA J. 24, 7-18.

Brown, G., Raymond, C.M., 2014. Methods for identifying land use conflict potential using participatory mapping. Landsc. Urban Plan. 122, 196-208.

Brown, G., Montag, J.M., Lyon, K., 2011. Public Participation GIS: A method for identifying ecosystem services. Soc. Nat. Resour. 25, 633-651.

Bryan, B.A., Raymond, C.M., Crossman, N.D., Macdonald, D.H., 2010. Targeting the management of ecosystem services based on social values: Where, what, and how? Landsc. Urban Plan. 97, 111-122.

Bryan, B.A., Raymond, C.M., Crossman, N.D., King, D., 2011. Comparing spatially explicit ecological and social values for natural areas to identify effective conservation strategies. Conserv. Biol. 25, 172-181.

Calhoun, C., 1992. Habermas and the public sphere. MIT Press, Cambridge, MA. CBC (Canadian Broadcasting Corporation), 2014. Northern Gateway Pipeline Approved with 209 Conditions. CBCnews. June 17, 2014. Available from: http://www.cbc.ca/ news/politics/northern-gateway-pipeline-approved-with-209-conditions-1.2678285.

Chan, K.M.A., Guerry, A.D., Balvanera, P., Klain, S., Satterfield, T., Basurto, X., Bostrom, A., Chuenpagdee, R., Gould, R., Halpern, B.S., Levine, J., Norton, B., Ruckelshaus, M., Russell, R., Tam, J., 2012a. Where are cultural and social in ecosystem services? A framework for constructive engagement. Bioscience 62, 744-756.

Chan, K.M.A., Satterfield, T., Goldstein, J., 2012b. Rethinking ecosystem services to better address and navigate cultural values. Ecol. Econ. 74, 8-18.

Church, A., Fish, R., Haines-Young, R.,Mourato, S., Tratalos, J., Stapleton, L., Willis, C., Coates, P., Gibbons, S., Leyshon, C., Potschin, M., Ravenscroft, N., Sanchis- Guarner, R., Winter, M., Kenter, J., 2014. UK National Ecosystem Assessment Follow-on. Work Package Report 5: Cultural ecosystem services and indicators. UNEP-WCMC, LWEC, UK.

Cooke, 2001. The Social Psychological Limits of Participation? In: Cooke, B., U.K. (Eds.), Participation: The New Tyranny? Zed Books, London, pp. 102-121.

Davies, B.B., Hodge, I.D., 2012. Shifting environmental perspectives in agriculture: Repeated $\mathrm{Q}$ analysis and the stability of preference structures. Ecol. Econ. 83, 51-57. 
Dietz, T., Stern, P.C., Dan, A., 2009. How deliberation affects stated willingness to pay for mitigation of carbon dioxide emissions: An experiment. Land Econ. 85, 329-347.

Douglas, M., Wildavsky, A., 1983. Risk and Culture: An Essay on the Selection of Technological and Environmental Dangers. University of California Press, London.

Edwards, D.M., Jay, M., Jensen, F.S., Lucas, B., Marzano, M., Montagne, C., Peace, A., Weiss, G., 2012. Public preferences across Europe for different forest stand types as sites for recreation. Ecol. Soc. 17.

Enbridge Northern Gateway Piplelines, 2010. Environmental and Socio-Economic Assessment (ESA) - Human Environment. Vancouver, BC.

Fagerholm, N., Käyhkö, N., 2009. Participatory mapping and geographical patterns of the social landscape values of rural communities in Zanzibar, Tanzania. Int. J. Geogr. 187 (1), 43-60.

Fagerholm, N., Käyhkö, N., Ndumbaro, F., Khamis, M., 2012. Community stakeholders' knowledge in landscape assessments - Mapping indicators for landscape services. Ecol. Indic. 18, 421-433.

Fazey, I., Bunse, L., Msika, J., Pinke, M., Preedy, K., Evely, A.C., Lambert, E., Hastings, E., Morris, S., Reed, M.S., 2014. Evaluating knowledge exchange in interdisciplinary and multi-stakeholder research. Glob. Environ. Chang. 25, 204-220.

Fischer, J., Dyball, R., Fazey, I., Gross, C., Dovers, S., Ehrlich, P.R., Brulle, R.J., Christensen, C., Borden, R.J., 2012. Human behavior and sustainability. Front. Ecol. Environ. 10, 153-160.

Flint, C.G., Kunze, I., Muhar, A., Yoshida, Y., Penker, M., 2013. Exploring empirical typologies of human-nature relationships and linkages to the ecosystem services concept.

Landsc. Urban Plan. 120, 208-217.Forrester, J., 1999. The deliberative practitioner: Encouraging participatory planning process. MIT Press, Cambridge, MA.

Frame, B., Brown, J., 2008. Developing post-normal technologies for sustainability. Ecol.

Econ. 65, 225-241.

Frame, B., O'Connor,M., 2011. Integrating valuation and deliberation: the purposes of sustainability assessment. Environ. Sci. Policy 14, 1-10.

Funtowicz, S.O., Ravetz, J.R., 1990. Uncertainty and Quality in Science for Policy. Kluwer, Dordrecht.

Funtowicz, S.O., Ravetz, J.R., 1991. A newscientific methodology for global environmental issues. In: Costanza, R. (Ed.), Ecological Economics: The Science and Management of Sustainability. Columbia University Press, New York.

Funtowicz, S.O., Ravetz, J.R., 1993. Science for the post-normal age. Futures 25, 739-755.

Funtowicz, S.O., Ravetz, J.R., 1994. The worth of a songbird: ecological economics as a postnormal science. Ecol. Econ. 10, 197-207.

Gaskell, G., 2001. Attitudes, social representations and beyond. In: Deaux, K., Philogene, G. (Eds.), Representations of the Social: Bridging Theoretical Traditions. Blackwell Publishing, Oxford, pp. 228-241.

Gill, D.A., Ritchie, L.A., 2011. A Social Impact Assessment of the Enbridge Northern Gateway Pipeline Project on the Gitga'at First Nation. Unpublished Report. 
Submission to the Joint Review Panel for Review of the Enbridge Northern Gateway Project, on behalf of the Gitga' at First Nation, (Hartley Bay, BC).

Habermas, J., 1984. The Theory of Communicative Action. Beacon Press, Boston, MA.

Hernandez-Morcillo, M., Plieninger, T., Bieling, C., 2013. An empirical review of cultural ecosystem service indicators. Ecol. Indic. 29, 434-444.

Hockley, N., 2014. Cost-benefit analysis: A decision-support tool or a venue for contesting ecosystem knowledge? Environ. Plan. C 32 (2), 283-300.

Howarth, R.B., Wilson, M.A., 2006. A theoretical approach to deliberative valuation: Aggregation by mutual consent. Land Econ. 82, 1-16.

Ives, C.D., Kendal, D., 2014. The role of social values in the management of ecological systems. J. Environ. Manag. 144C, 67-72.

Janis, I.L., 1972. Victims of groupthink: A psychological study of foreign-policy decisions and fiascoes. Houghton Mifflin, Oxford, UK.

Kallis, G., Gómez-Baggethun, E., Zografos, C., 2013. To value or not to value? That is not the question. Ecol. Econ. 94, 97-105.

Kaplowitz, M.D., Hoehn, J.P., 2001. Do focus groups and individual interviews reveal the same information for natural resource valuation? Ecol. Econ. 36, 237-247.

Karjalainen, T.P., Marttunen, M., Sarkki, S., Rytkonen, A.-M., 2013. Integrating ecosystem services into environmental impact assessment: An analytic-deliberative approach. Environ. Impact Assess. Rev. 40, 54-64.

Kenter, J.O., Hyde, T., Christie,M., Fazey, I., 2011. The importance of deliberation in valuing ecosystem services in developing countries-Evidence from the Solomon Islands. Glob. Environ. Chang. 21, 505-521.

Kenter, J.O., O'Brien, L., Hockley, N., Ravenscroft, N., Fazey, I., Irvine, K.N., Reed, M.S., Christie, M., Brady, E., Bryce, R., Church, A., Cooper, N., Davies, A., Evely, A., Everard, M., Fish, R., Fisher, J.A., Jobstvogt, N., Molloy, C., Orchard-Webb, J., Ranger, S., Ryan, M., Watson, V., Williams, S. 2014. What are shared and social values of ecosystems? Ecol. Econ. (submitted for publication).

Kenter, J.O., Reed, M.S., Irvine, K.N., O'Brien, E., Brady, E., Bryce, R., Christie, M., Church, A., Cooper, N., Davies, A., Hockley, N., Fazey, I., Jobstvogt, N.,Molloy, C., OrchardWebb, J., Ravenscroft, N., Ryan, M., Watson, V., 2014. UK National Ecosystem Assessment Follow-on.Work Package Report 6: Shared, Plural and Cultural Values of Ecosystems. UNEP-WCMC, LWEC, UK (Available from: http://www.lwec.org.uk/sharedvalues).

Kerr, G.N., Swaffield, S.R., 2012. Identifying cultural service values of a small river in the agricultural landscape of Canterbury, New Zealand, using combined methods. Soc. Nat. Resour. 25, 1330-1339.

Klain, S.C., Chan, K.M.A.A., 2012. Navigating coastal values: Participatory mapping of ecosystem services for spatial planning. Ecol. Econ. 82, 104-113.

Kothari, U., 2001. Power, Knowledge and Social Control in Participatory Development. In: Cooke, B., Kothari, U. (Eds.), Participation: The New Tyranny? Zed Books, London, pp. 139-152. 
Maes, J., Paracchini, M.L., Zulian, G., Dunbar, M.B., Alkemade, R., 2012. Synergies and trade-offs between ecosystem service supply, biodiversity, and habitat conservation status in Europe. Biol. Conserv. 155, 1-12.

Maier, N.R., 1967. Assets and liabilities in group problem solving: The need for an integrative function. Psychol. Rev. 74, 239-249.

Martín-López, B., Iniesta-Arandia, I., García-Llorente, M., Palomo, I., Casado-Arzuaga, I., Amo, D.G. Del, Gómez-Baggethun, E., Oteros-Rozas, E., Palacios-Agundez, I., Willaarts, B., González, J.A., Santos-Martín, F., Onaindia, M., López-Santiago, C., Montes, C., 2012. Uncovering ecosystem service bundles through social preferences. PLoS ONE 7 (6), e38970.

MEA, 2005. Ecosystems and human well-being. The Millennium Ecosystem Assessment Series. Island Press, Washington, D.C.

Milcu, A.I., Hanspach, J., Abson, D., Fischer, J., 2013. Cultural ecosystem services: A literature review and prospects for future research. Ecol. Soc. 18 (3), 44-77.

Moscovici, S., 1972. Theory and society in social psychology. In: Isreal, J., Tajfel, H. (Eds.), The Context of Social Psychology: A Critical Assessment. Academic Press, London, UK.

Moscovici, S., 1984. The phenomenon of social representations. In: Farr, R., Moscovici, S. (Eds.), Social Representations. Cambridge University Press, Cambridge, UK, pp. $3-$ 69.

Moscovici, S., 1988. Notes towards a description of social representations. Eur. J. Soc. Psychol. 18, 211-250.

Nahuelhual, L., Carmona, A., Lozada, P., Jaramillo, A., Aguayo, M., 2013. Mapping recreation and ecotourism as a cultural ecosystem service: An application at the local level in Southern Chile. Appl. Geogr. 40, 71-82.

National Energy Board, 2013. Update. Report of the Joint Review Panel for the Enbridge Northern Gateway Project. Canadian Environmental Assessment Agency (December 19, www.gatewaypanel.review-examen.gc.ca/clf-nsi/hm-eng.html).

Nielsen-Pincus, M., Goldberg, C.S., Pocewicz, A., Force, J.E.,Waits, L.P., Morgan, P., Vierling, L., 2010. Predicted effects of residential development on a northern Idaho landscape under alternative growth management and land protection policies. Landsc. Urban Plan. 94, 255-263.

Norgaard, R.B., 2010. Ecosystem services: From eye-opening metaphor to complexity blinder. Ecol. Econ. 69, 1219-1227.

Oteros-Rozas, E., Martín-López, B., González, J.A., Plieninger, T., López, C.A., Montes, C., 2014. Socio-cultural valuation of ecosystem services in a transhumance socialecological network. Reg. Environ. Chang. 14, 1269-1289.

Pacific Wild, 2014. Enbridge and the JRP. http://pacificwild.org/site/our-work/no-tankers/ enbridge-joint-review-panel.html.

Pielke, R., 2007. The Honest Broker. Cambridge University Press, New York.

Plieninger, T., Bieling, C. (Eds.), 2012. Resilience and the Cultural Landscape: Understanding and Managing Change in Human-Shaped Environments. Cambridge University Press, Cambridge. 
Plieninger, T., Dijks, S., Oteros-Rozas, E., Bieling, C., 2013. Assessing, mapping, and quantifying cultural ecosystem services at community level. Land Use Policy 33, 118129.

Ravetz, J.R., 1987. Usable knowledge, usable ignorance: incomplete science with policy implications. In: Clark, W.C., Munn, R.E. (Eds.), Sustainable Development of the Biosphere. Cambridge University Press, Cambridge, pp. 415-432.

Raymond, C.M., Brown, G., 2006. Amethod for assessing protected area allocations using a typology of landscape values. J. Environ. Plan. Manag. 49, 797-812.

Raymond, C.M., Brown, G., 2011. Assessing spatial associations between perceptions of landscape value and climate change risk for use in climate change planning. Clim. Change 104, 653-678.

Raymond, C.M., Bryan, B.A., MacDonald, D.H., Cast, A., Strathearn, S., Grandgirard, A., Kalivas, T., 2009. Mapping community values for natural capital and ecosystem services. Ecol. Econ. 68, 1301-1315.

Raymond, C.M., Fazey, I., Reed, M.S., Stringer, L.C., Robinson, G.M., Evely, A.C., 2010. Integrating local and scientific knowledge for environmental management. J. Environ. Manag. 91, 1766-1777.

Raymond, C.M., Singh, G.G., Benessaiah, K., Bernhardt, J.R., Levine, J., Nelson, H., Turner, N. J., Norton, B., Tam, J., Chan, K.M.A., 2013. Ecosystem services and beyond: Using multiple metaphors to understand human-environment relationships. Bioscience 63, 536-546.

Reed, M.S., 2008. Stakeholder participation for environmental management: A literature review. Biol. Conserv. 141, 2417-2431.

Reed, M.S., Graves, A., Dandy, N., Posthumus, H., Hubacek, K., Morris, J., Prell, C., Quinn, C. H., Stringer, L.C., 2009. Who's in and why? A typology of stakeholder analysis methods for natural resource management. J. Environ. Manag. 90, 1933-1949.

Satterfield, T., Robertson, L., Turner, N.J., 2011. Being Gitka'a'ata: A Baseline Report on Gitka'a'ataWay of Life, a Statement of Cultural Impacts Posed by the Northern Gateway Pipeline, and a Critique of the ENGP Assessment Regarding Cultural Impacts.

Schaich, H., Bieling, C., Plieninger, T., Biding, C., 2010. Linking ecosystem serviceswith cultural landscape research. GAIA 19, 269-277.

Sherrouse, B.C., Clement, J.M., Semmens, D.J., 2011. A GIS application for assessing, mapping, and quantifying the social values of ecosystem services. Appl. Geogr. 31, $748-760$.

Sherrouse, B.C., Semmens, D.J., Clement, J.M., 2014. An application of Social Values for Ecosystem Services (SolVES) to three national forests in Colorado and Wyoming. Ecol. Indic. 36, 68-79.

Spash, C.L., 2007. Deliberative monetary valuation (DMV): Issues in combining economic and political processes to value environmental change. Ecol. Econ. 63, 690-699.

Stein, S.M., Harper, T.L., 2003. Power, trust, and planning. J. Plan. Educ. Res. 23, 125-139.

Sultana, P., Abeyasekera, S., 2008. Effectiveness of participatory planning for community management of fisheries in Bangladesh. J. Environ. Manag. 86, 201-213. 
UK NEA, 2014. UK National Ecosystem Assessment, Follow on Phase: Synthesis Report, (Cambridge, UK).

Van Riper, C.J., Kyle, G.T., Sutton, S.G., Barnes, M., Sherrouse, B.C., 2012. Mapping outdoor recreationists' perceived social values for ecosystem services at Hinchinbrook Island National Park, Australia. Appl. Geogr. 35, 164-173.

Verburg, R., Rodrigues Filho, S., Debortoli, N., Lindoso, D., Nesheim, I., Bursztyn, M., 2014. Evaluating sustainability options in an agricultural frontier of the Amazon using multicriteria analysis. Land Use Policy 37, 27-39.

Whitehead, A.L., Kujala, H., Ives, C.D., Gordon, A., Lentini, P., Wintle, B., Nicholson, E., Raymond, C.M., 2014. Integrating biological and social valueswhen prioritising places for biodiversity conservation. Conserv. Biol. http://dx.doi.org/10.1111/cobi.12257. 


\section{Figure 1.}

Instrumental valuation involving a single social representation (assumes a homogenous regional population).

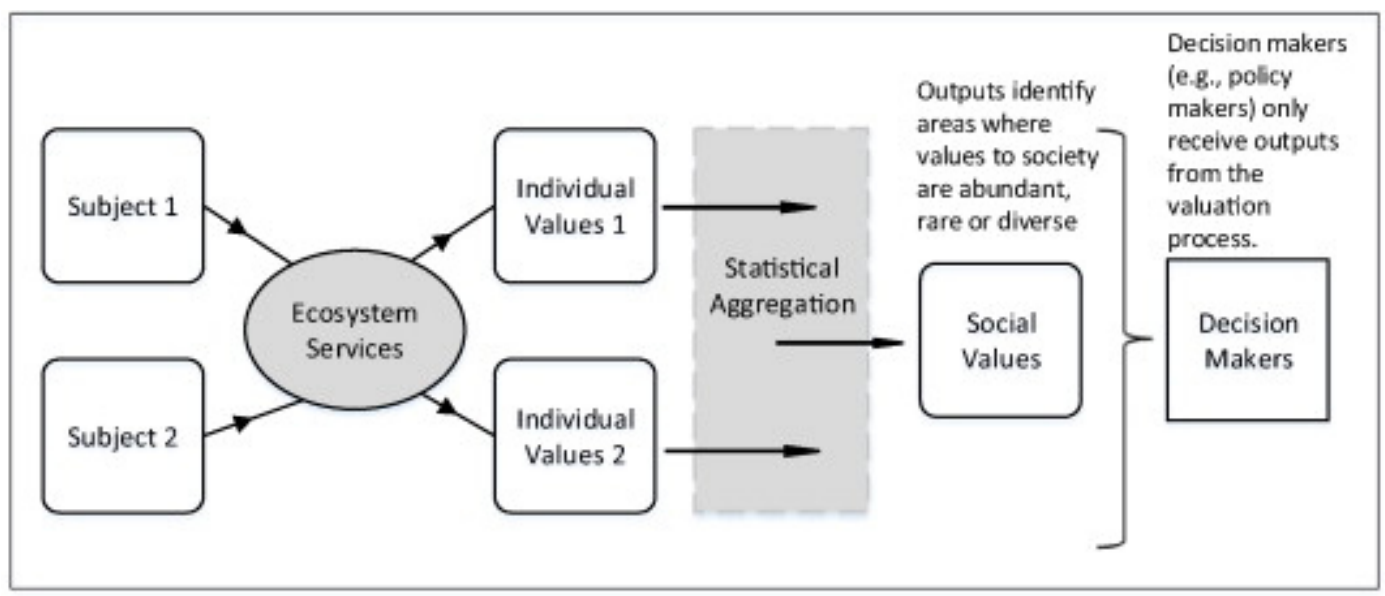




\section{Figure 2.}

Instrumental valuation involving dual or multiple social representations.

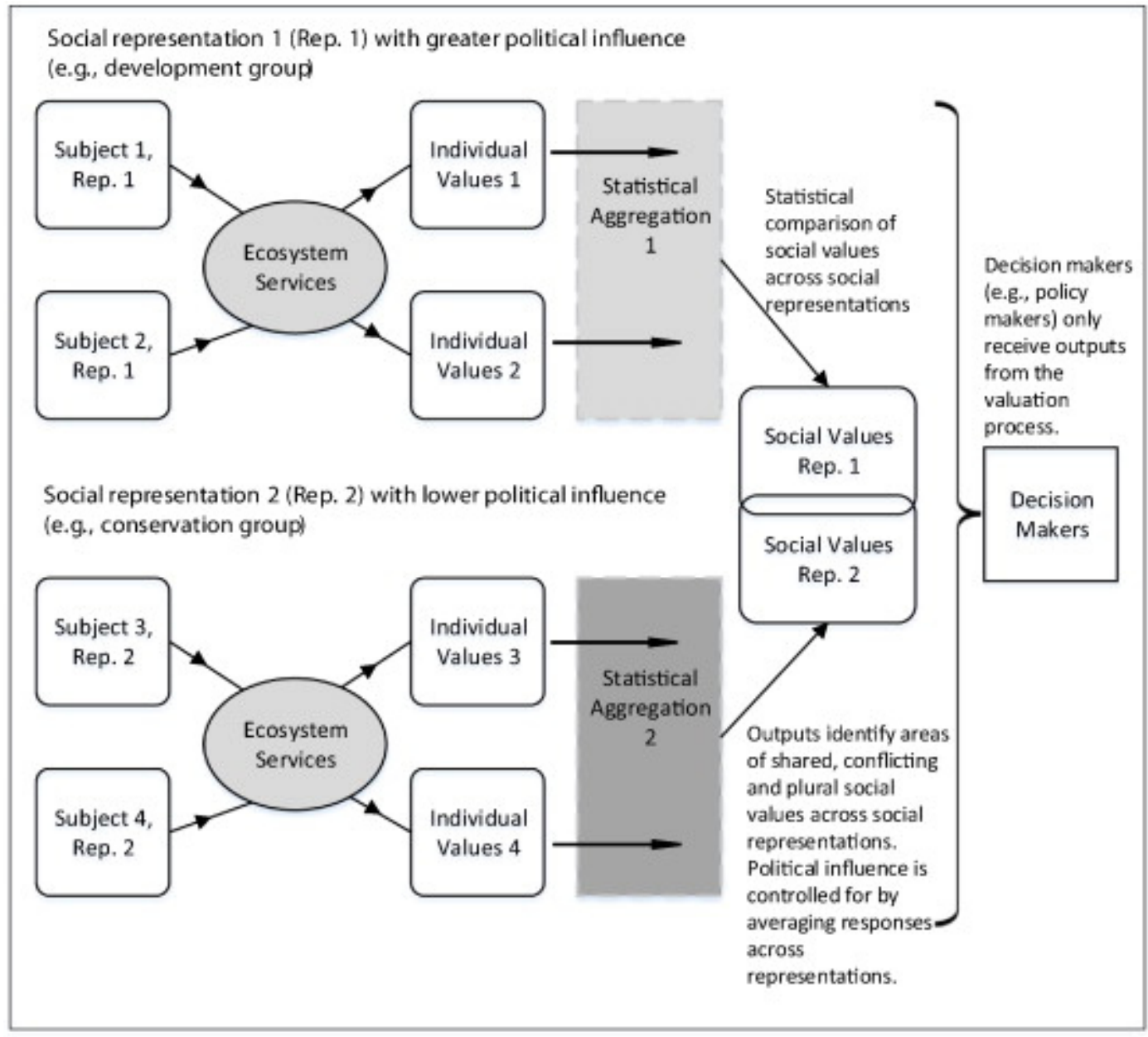


Figure 3.

Deliberative valuation involving individuals (subjects) from a single representation.

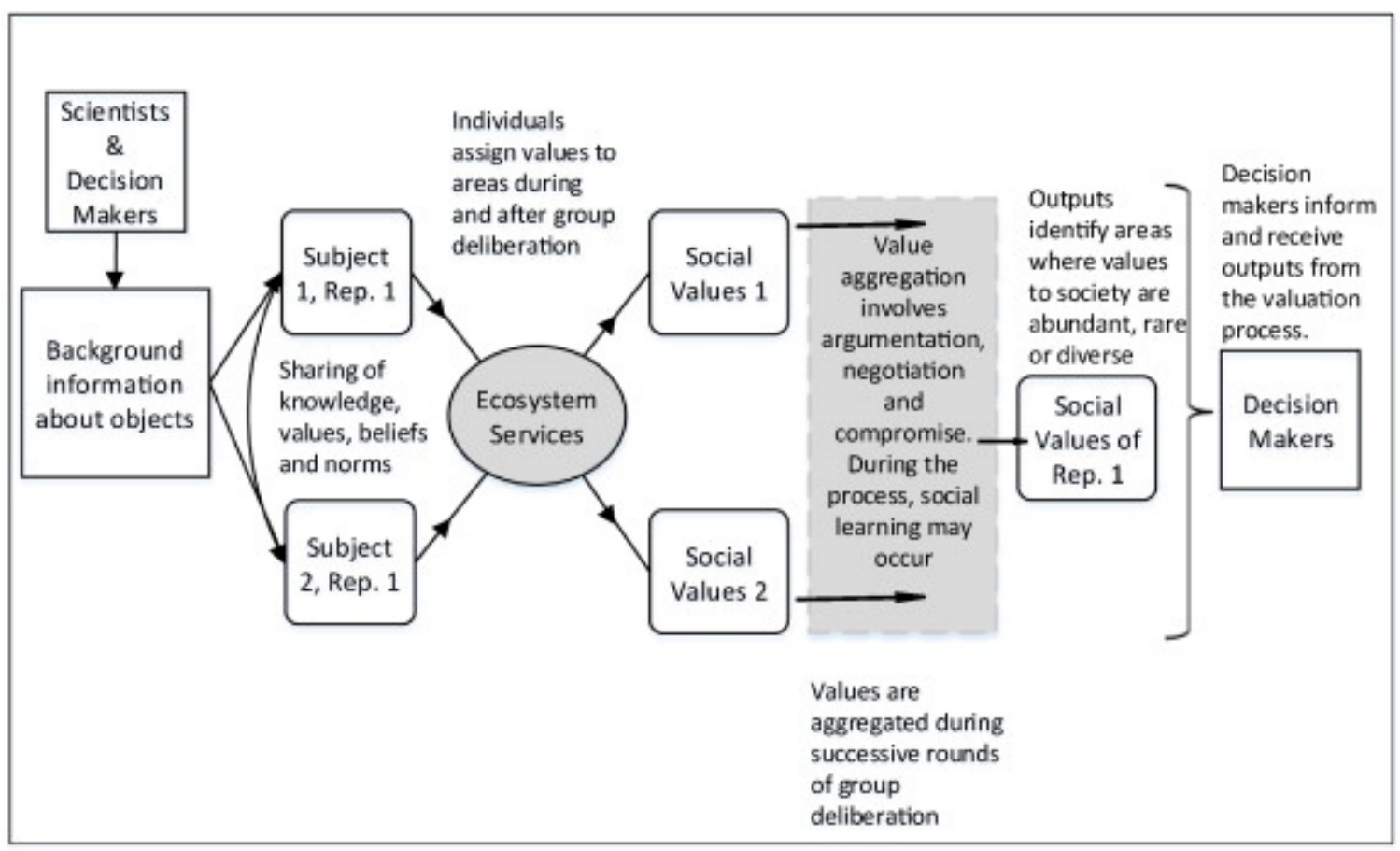




\section{Figure 4.}

Deliberative valuation involving individuals (subjects) across dual or multiple social representations.

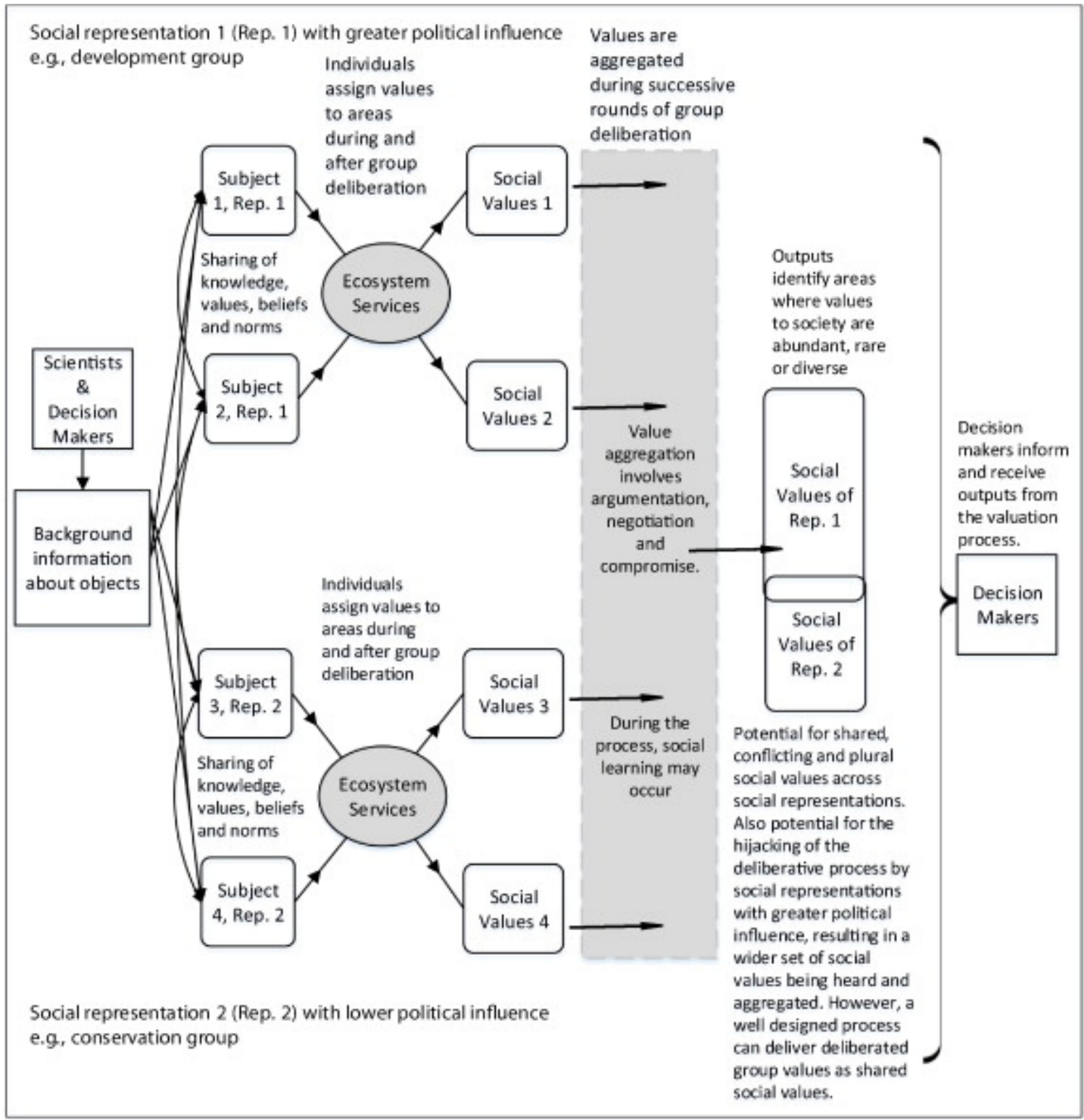


Table 1.

A summary of the distinctions between instrumental and deliberative paradigms.

\begin{tabular}{|c|c|c|c|c|}
\hline Paradigm & $\begin{array}{l}\text { Perspective on } \\
\text { rationality }\end{array}$ & $\begin{array}{l}\text { Process of value } \\
\text { elicitation }\end{array}$ & $\begin{array}{l}\text { Type of } \\
\text { representativeness } \\
\text { sought }\end{array}$ & \begin{tabular}{|l} 
Degree of \\
involvement of \\
decision \\
makers
\end{tabular} \\
\hline Instrumental & \begin{tabular}{|l} 
Instrumental. \\
Values can be \\
objectively measured, \\
quantified and traded- \\
off. \\
Focus on contextual \\
values, transcendental \\
values not usually \\
relevant. Assumption \\
that rational outcomes \\
do not require social \\
exchange.
\end{tabular} & $\begin{array}{l}\text { Focus on rating and } \\
\text { ranking contextual } \\
\text { values. Individual } \\
\text { values aggregated } \\
\text { arithmetically into } \\
\text { social values. }\end{array}$ & $\begin{array}{l}\text { Statistical. } \\
\text { Key considerations } \\
\text { are sample sizes and } \\
\text { representativeness } \\
\text { across age, gender, } \\
\text { income etc. }\end{array}$ & $\begin{array}{l}\text { Decision } \\
\text { makers mainly } \\
\text { seen as end } \\
\text { users, not } \\
\text { involved in } \\
\text { generating } \\
\text { evidence. }\end{array}$ \\
\hline Deliberative & \begin{tabular}{|l} 
Communicative. \\
Reason is process and \\
context-dependent. \\
Evaluation takes place \\
through the \\
communication of social \\
constructions and \\
through social \\
representations, without \\
claim to objectivity. \\
Focus on both \\
transcendental and \\
contextual values. \\
Emphasis is on \\
participation and social \\
learning.
\end{tabular} & $\begin{array}{l}\text { Social values are } \\
\text { formed through a } \\
\text { structured process of } \\
\text { communication, } \\
\text { participation, social } \\
\text { learning and } \\
\text { negotiation. } \\
\text { Scientists, among } \\
\text { other experts, are } \\
\text { often active } \\
\text { participants in the } \\
\text { deliberative process. }\end{array}$ & \begin{tabular}{|l||} 
Political. \\
Key considerations \\
are whether are \\
relevant interests are \\
represented within \\
the process and \\
whether the process is \\
adequately managed.
\end{tabular} & $\begin{array}{l}\text { Decision } \\
\text { makers help } \\
\text { frame research } \\
\text { and may } \\
\text { participate in or } \\
\text { help facilitate } \\
\text { deliberations. }\end{array}$ \\
\hline
\end{tabular}


Table 2.

A continuum of valuation approaches to be considered when assessing cultural ecosystem services.

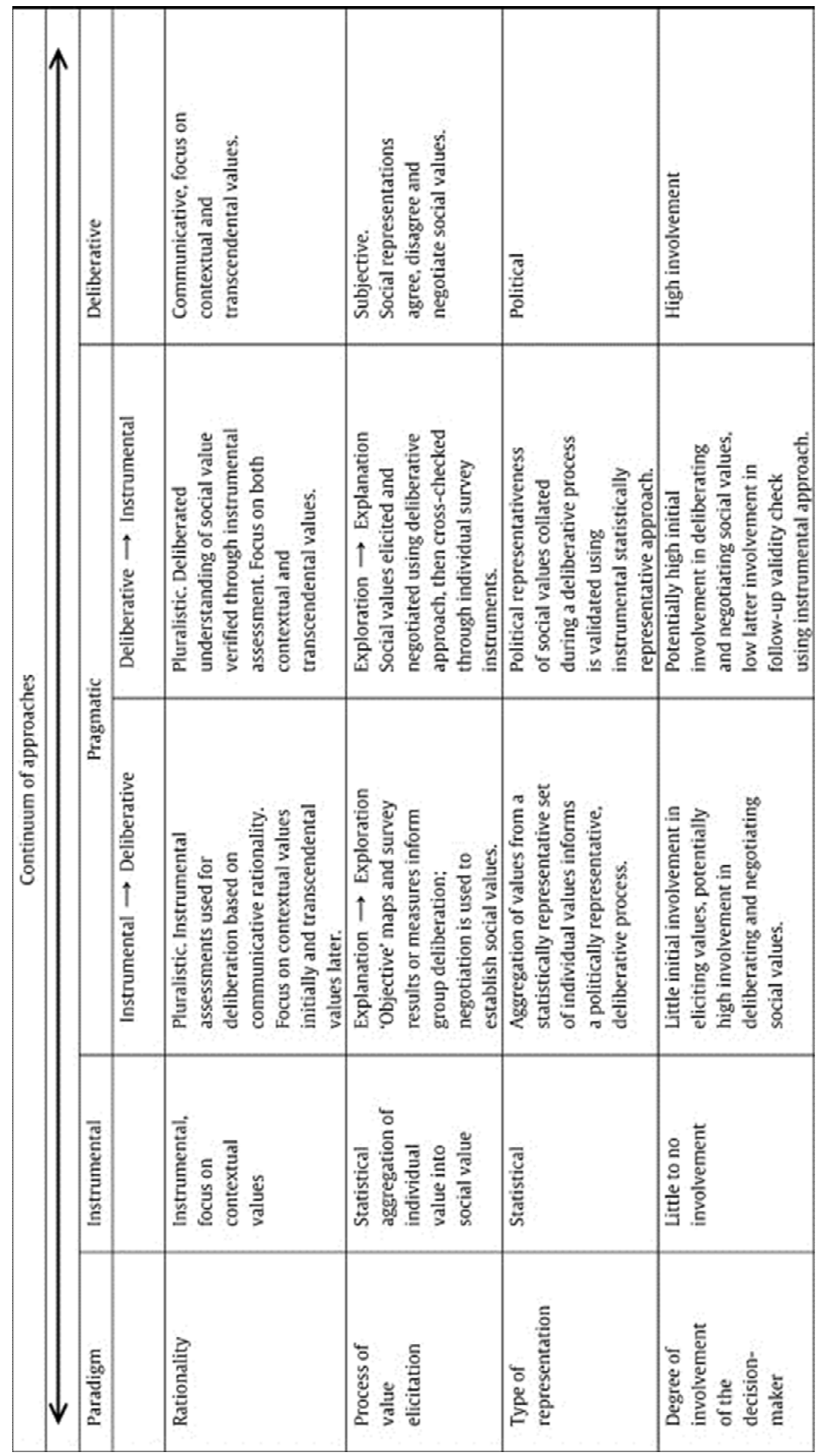

